\title{
Enhanced Cloud Computing Framework to Improve the Educational Process in Higher Education: A case study of Helwan University in Egypt
}

\author{
Dr. Ayman E. Khedr, Dr. S. A. Kholeif, Shrouk H. Hessen \\ Department of Information Systems, \\ Faculty of Computers and Information, \\ Helwan University, Cairo, Egypt \\ ayman_khedr@helwan.edu.eg \\ sherifkholeif@yahoo.com \\ shroukhessen@gmail.com
}

\begin{abstract}
Cloud Computing (CC) is an extension of a paradigm where the capabilities of applications are exposed as services. $\mathrm{CC}$ has spread dramatically because of the different features that make it the target of most Cloud Service Providers. In cloud computing the data stored in the storage area and accessed by the organizations based on their demand from the internet. Cloud computing with virtualization is removing any additional operational expense or investing in assets capital by automating the requested services. Currently, Cloud computing has become a technology with the potential for coping with the problems of e-learning. This study, therefor, attempts to explore the possible effects and measures of how educational institutions can benefit from CC. For that purpose, this study implements an enhanced framework for e-learning system based on cloud. This enhaced framework can be applied everywhere where there is a need for intensive teaching and learning in higher education instituations to improve their educational process. The applied case study findings of the adoption of the enhanced framework equate the study expectations, where the student's satisfaction significantly increased compared with the existing system.
\end{abstract}

\section{KEYWORDS}

Cloud Computing, E-Learning, Adaption processes and E-learning based cloud

\section{Council for Innovative Research}

\section{Peer Review Research Publishing System}

\section{Journal: INTERNATIONAL JOURNAL OF COMPUTERS \& TECHNOLOGY}

Vol14, No.6

www.ijctonline.com, editorijctonline@gmail.com 


\section{INTRODUCTION}

Cloud Computing (CC) defines the feature given by computation resources through a computers network [1]. As for the technique of computing, the user's computer holds all the important software and data to perform all computing operations on computation resources and files. Consequently, the users of cloud computing virtually do not need to have any especial background or skills for make computing on files except minimal operating system with browser and excellent Internet connectivity to access their files and applications from online sources [2].

Currently, CC has spread dramatically [1] because of features that make it the target of most Cloud Service Providers (CSPs). However, there is no comprehensible definition or standard for cloud computing that all CSPs agree upon since each provider utilizes terminology based on its own product's portfolio. Despite several standardization efforts, there is no clear standard for CC [3].

The aim of this study is to implement an enhanced framework for e-learning based cloud to overcome the problems in the normal structure of e-learning and to enhance the existing Virtual Learning Environment (VLE) line up with a variety of services that in turn improves the educational process in educational institutions and help to) expand the VLE to match the whole students' requirements [4]. The remainder of this paper is structured as follows: section 2 gives a study background study and a brief overview of cloud computing, e-learning and the different factors concerning the adoption process of a new technology (e.g. cloud computing). Section 3 discusses the different literature view and prior work related to the research. Section 4 illustrates the proposed framework for e-learning based cloud whereas section 5 presents research methodology used in this study. Section 6 demonstrates the case study survey analysis and its related discussion. Finally, section 7 ends this paper with conclusion and future work.

\section{BACKGROUND}

The advances in computing, multimedia, and communication technologies provide an opportunity to build a selfgrowing, unit sharing virtual environment for teaching and learning [5][6]. Cloud computing is an extension of a paradigm where the capabilities of applications are exposed as services [7]. These services enable the development of scalable web applications in which dynamically scalable and often virtualized resources are provided as a service over the internet [8]. CC enables educational institutions that do not have the technical expertise to support their own infrastructure to get access to cloud computing on demand.

Eventually, there are clusters of factors affecting the effective adoption processes of a new technology in any institution. These clusters of factors are defined broadly as unpredictable and changeable variables/factors, the effects of which, on the adoption process, cannot exactly be estimated (positively or negatively). These different factors can be categorized into three homogeneous categories: external, internal and technology uncertainty factors [9]. These different clusters of factors are supporting or obstructing the adoption of a new technology such as cloud computing in our case. Prior studies investigated these factors in specific fields [10] [11]. Most of these studies approved on the following classification of uncertainty factors [4][10][11][12]:

i . External factors: these factors have effects on the introduction of a new technology to the different institutions (such as educational ones) and the adoption process related to it. There is a list of external factors to be considered, together with additional different factors that are related to the technology adoption process in different situations; namely: student satisfaction, governmental policies, competition, and cultural and educational environment.

ii. Internal factors: these factors are categorized into two common folds of factor categories; organizational factors, and personal attitudes or organizations employees' attitudes [13]. Mostly, literature permitted that there is a positive relationship between the educational institutions' size and market share, and technology adoption process [13][14].

lii. Technological factors: technological factors that affect the technology diffusion process, most often studied in relatively stable environments and related to technology acceptance, are: response time, flexibility, breakdowns or crashes, usability or ease of use, and usefulness [15]. The importance of choosing these factors and their folds is resulting from different experimental studies that have investigated the effect of these factors on the adoption of a new technology [4][16].

Educational institutions are beginning to have the advantage of existing applications hosted in cloud that enable their end users to perform tasks that have usually required site licensing, installation, and maintenance of individual software packages [7][17]. In addition, to make applications and services more productivity similar to YouTube, Google Docs and Spreadsheets, as well as a host of other browser-based applications, comprise a set of increasingly powerful cloud-based tools for user tasks that might need to do particularly in e-learning applications. Furthermore, it might be easy to share content created with these tools, both in terms of collaborating on its creation and distributing the completed work [17].

Currently, educational institutions need to tailor their services based on their students' individual requirements based on precise analysis and understanding of available historical data. Egyptian university are faced with different problems most of which are related to our research issue. Egyptian's educational institutions have to adopt cloud computing to create knowledge from their large volume of available historical data and expertise that can support the decision makers in achieving their goals. Egyptian universities are caused by all kind of unexpected changes in different levels (social, economic, technological and environmental) which, in its turn, caused various problems. These problems might be segmented and restated in the following three folds [4][12][18]: 
i. External problems: these problems are related to the decline in demand for universities services, and the increasing rate of students switching to foreign competitors. Some of these problems namely are: economic development that can affect student life in Egyptian university and the new means of using technologies as well as elearning based on these technologies.

ii. Internal problems: these problems concerned to the performance of different contact channels of the Egyptian state universities (e.g. employee, student affair staff, IT staff, web portals, call centers, etc.) in acquiring satisfied student and are based on available technology and employees' attitudes towards students. Moreover, there is little awareness of the cloud computing benefits within the management staff of the university.

iii. Technical problems; such as [4][12][18]:

Using the large volumes of available data with rich descriptions, to perform reliable inference of useful patterns.

Using available prior knowledge about the domain such as important field relations, user goals and patterns already known. Prior knowledge can significantly reduce the search in all knowledge related the education processes.

There are sometimes difficulties because data is stored in such a way that it is not compatible with newer systems that support the implementation of cloud computing.

Integration with other IT systems is of major necessity. This is a major challenge in Egyptian public university because at the moment most of Egyptian public university branches are not centrally connected and do not interact with each other.

Accordingly, there is this a need for an enhanced framework that has a better inclusive insight into the relationship between the successful adoption process of CC and its impact on the higher education in Egypt emphasis on elearning based on cloud computing. As stated earlier, the specific objective of the study analysis is therefore to identify the determinants of the introduction of a new technology and to examine the effects of the various explanatory variables on the introduction process. To gain the most useful benefits of the implementation of cloud computing in higher education it should first be analyzed the introduction from both from two point of views the benefits, and risks and limitations as well. So, it could get rid of the risks and limitation to gain great benefits of adaption.

\section{LITERRATURE REVIEW}

Cloud computing with virtualization is removing any additional operational expense or investing in assets capital by automating the requested service [19][20]. In addition, the cost reduction of using the cloud could save consuming time energy consumption, and effort in building infrastructure [21][22][23]. Cloud services can be categorized into three main service models. These services, with each one considered a layer in the cloud, are illustrated in the following points [8][24]:

i. Infrastructure as a Service (laaS) is one of the three fundamental service models of cloud computing. In this model the users are allocated with computing resources in order to run their applications. The computing services are provided in a virtualized environment. The best known example of laaS is Amazon Cloud Formation, Amazon EC2. It can be implemented by utilizing the concepts like enterprise infrastructure, cloud hosting, and Virtual Data Centers (VDC). Network as a Service (NaaS) is a category of cloud infrastructure services where the user can use the network connectivity as services [25][26][27][28].

ii. Platform as a Service (PaaS) is a category of cloud computing service model that provides the developers a platform to build and use applications and services by using a communication network. PaaS services are available in the cloud and accessed by users by using web browsers. In this model, cloud service provides a platform which includes operating system, programming language execution environment, database, and web server. The users can use these services to improve and install their own applications [25][26][27][28].

iii. Software as a Service (SaaS) is the third cloud service model that provides a platform in which the users access the software from the cloud. The users of SaaS will not have to manage the cloud infrastructure and platform on which the application is running. The software installation and operation is the responsibility of the service providers and already available by using laaS and PaaS. This is typically end user applications delivered on demand over a network on a pay per use basis [29][30][31][32].

Cloud computing have four different types of cloud techniques which vary on their methods of deployment of computing [4][33][34]:

Public cloud: it provides cloud services in a virtualized environment accessible via Web applications or Web services through internet (Public Network). The cloud services and cloud resources are accessed from very large resource pools that are shared by all the end users.

Hybrid cloud: a hybrid cloud provides an integrated environment accessible to both private and public cloud functionalities. For better utilization of resources an organization can deploy public cloud services along with private cloud. 
Private cloud: a private cloud provides a distinct and secure cloud based environment in which only the authentic users within an organization can access. It makes the use of virtualization within the private area. It is provided and managed by the organization or a third party, and can be deployed according to the requirement.

Community cloud: a community cloud provides a different and protected environment where organizations with similar requirements share a common cloud infrastructure. So it is called as generalization of a private cloud where a private cloud infrastructure is only accessible to permissible users. It is provided and managed by the organization or a third party, and can be deployed according to the requirement.

\section{E-learning Based Cloud}

Cloud computing is a technology that took its shape by enhancing the existing e-learning technologies and methodologies. Educational institutions are adapting the e-learning for improving the ability of other regular educational degree programs as well as the online ones. Cloud computing transmits e-learning to the next level of IT world [4]. E-learning environment is an environment that offers a wide range of e-learning applications to students to get the access, the materials, and the tools related to their studies. There is a set of tools called Learning Management Systems (LMS) that is typically used with e-learning. Currently, prior studies developed several surveys about the usability of e-learning in such educational institutions in Egypt [35]. LMS is an e-learning platform which is considered as an important part of e-learning solutions from the university's viewpoint however LMS is software that automates the administration of training events.

E-learning based cloud is the sub division of cloud computing in the educational field for e-learning systems. Elearning based cloud has the whole set of provisions such as hardware and software resources to enhance the traditional e-learning infrastructure [36]. E-learning based cloud architecture and its five components are illustrated in figure 1[36]:

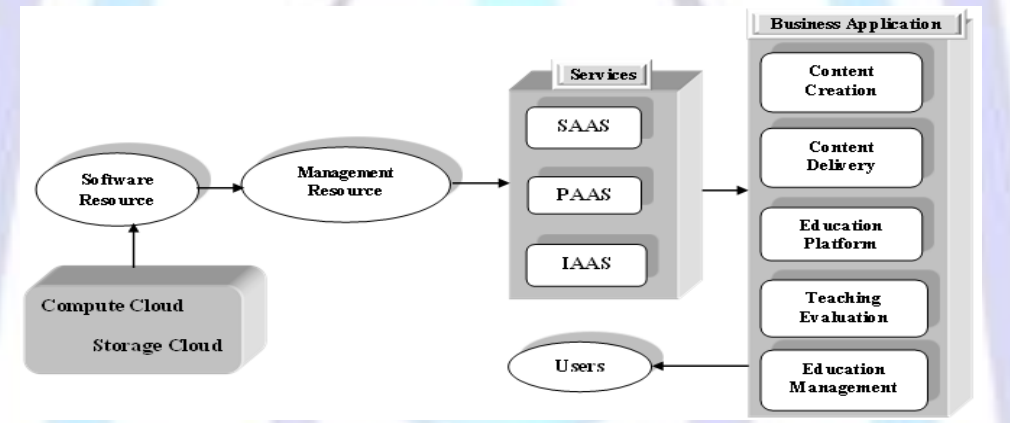

Fig. 1: Architecture of E-learning based cloud

Source: Laisheng and Zhengxia, 2011; Khedr, Kholeif and Hessen, 2015

These five components for e-learning based cloud framework, as depicted in figure 1, are namely; developing the knowledge base about cloud computing, evaluating the present stage of the university, experimenting with the cloud computing solutions and choosing the cloud computing solution, implementation and management of the cloud computing solution [37]. Meanwhile, there are three layers for building framework to apply e-learning based cloud that could be put into account to take us to the enhanced the existing framework for e-learning based cloud. These three layers are as follows [24]:

i. The base layer of e-learning cloud: the base layer of e-learning cloud allows the hardware layer to be similar to the internet, to make the hardware resources shared and accessed as data resources in a secure and scalable way. Virtualization technology separates the physical hardware from operating system, which one key user can make computing and storage capacity of the existing server into smaller size and re-integration, to improve the utilization and flexibility of IT resource.

ii. The platform layer of e-learning cloud: with the support of the powerful hardware, platform layer carries out the tasks of data storage, computing, software development and business intelligence processing that have been difficult to complete. Students can choose the devices and the number of devices according to the complexity of dealing with the content.

iii. The application layer of e-learning cloud: E-learning cloud space, users can access to digital services transparently at any time in anywhere. The users can obtain the required network and computing services very naturally at any position. The cloud and physical space will be integrated because of ubiquitous computing capability.

\section{PROPOSED FRAMEWORK FOR E-LEARNING BASED CLOUD}

Cloud computing based solution for VLE combines inclusive range of technologies, and tools to develop a collaborative tool for education process. So, the enhanced framework allows the exchange of educational content and integrate different educational approaches to learning and teaching under the same environment. The research enhanced model attempt to achieve the following objectives [4][7]: 
Estimating what the impact of cloud computing will be, this in turn requires knowing the facts about the capability of the educational institutions staff, the adoption processes of CC and its surrounding factors that effect on the implementation of e-learning based cloud. computing.

Exploring the essential changes that fit with the implementation process to gain the effective use of the cloud

As for educational institutions, cloud computing offers a cost-effective solution to the problem of how to provide services, data storage, and computing power to a growing number of internet users without investing capital in physical machines, which need to be maintained and upgraded on-site.

The research enhanced framework emphasis is on how we can combine VLE to use cloud techniques, private cloud and others service from public cloud to improve the educational process. The implementing of could computing leads to an enhanced accumulative model in which there is the VLE system with suitable services linked with VLE, based on changing business requirements. Using such enhanced model allowed avoiding lock-in; likewise it gave us the ability to secure the educational institutions critical data and services by hosting them on the educational institutions' servers without having to give them to a third-party to be under control. By highlighting the how part, it can proceed to the details of the enhanced framework layers and architecture. Figure 2shows the main components of the research enhanced framework. These components are as follows [4]:

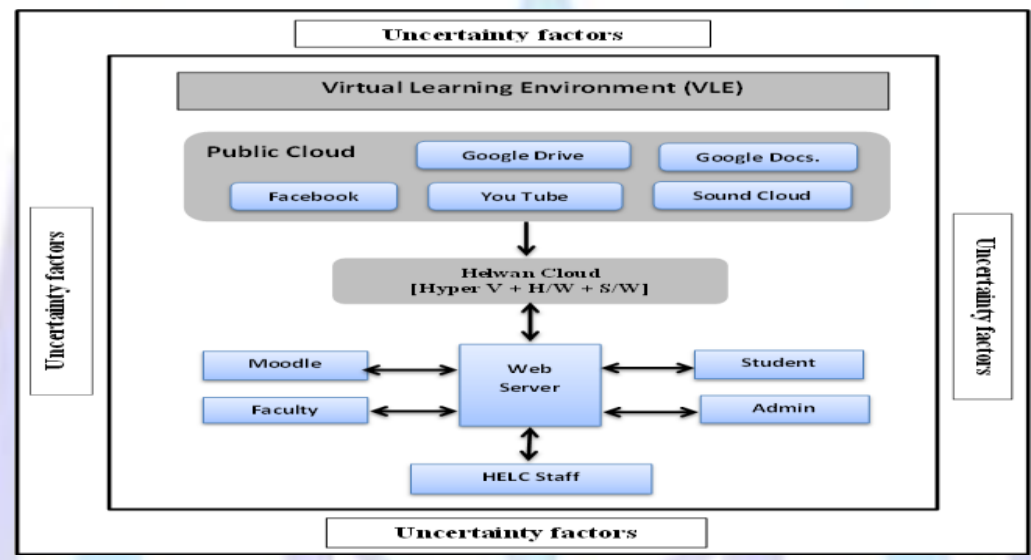

Fig. 2: Enhanced framework for e-learning based cloud

Source adapted from: Khedr, Kholeif and Hessen, 2015

Users: they divided into "students and faculty" and represent the system users that have authorized access over all or part of the faculties' resources.

Web server: it contains the academy virtual learning system called Moodle also it contains the faculties confidential data that requires more control and likewise need to be secured from the faculties, without having to give them to a third-party cloud provider to be under their control.

Cloud SaaS Layer: it contains the public providers' services, as example "Google Docs", it's represent a range of tools for teaching and learning needed for classrooms. Google drive is used to give the students and faculty free storage space to put their data in and to share it with others. Facebook and twitter could be used for sign up and login to the Moodle. Also, it can be used for sharing information and make comments, YouTube used to play videos and faculty tutorial, Sound Cloud is used for playing the audio media files and Skype could be used for video calls between the students.

\section{RESEARCH METHODOLOGY}

The research methodology of this research is considered Helwan University as a site of analysis. The units of analysis are Helwan E-learning Center (HELC) and Helwan Scientific Computing Center (HSCC) which is considered as a research case study. Additionally, the research conducted three times surveys; the first was planned as a pilot study survey, the second survey was for measuring the general attitudes and opinions from two different views; students and HELC staff, while the third time survey was for re-measuring the general attitudes and opinions from two different views; students and staff after the full implementation of cloud computing.

The SERVQUAL instrument is adapted to measure service quality in two different times: first time was for measuring the services that provided by existing system offered by HELC to evaluate the students' satisfactions in Helwan University in $2013 / 2014$ and the second time was in the most recently adoption process of cloud computing (Helwan Cloud for e-learning) to evaluate the newest students' satisfactions from current services offered this time by Helwn Scientific Computing Center (HSCC) in 2014/2015 after the fully introduction of cloud computing in e-learning. In the early adoption, the questionnaire has been measured the students' views by taking a sample from two different facilities in Helwan University; the Faculty of Computers and Information (FCI) and the Faculty of Commerce and Business Administration, Business Information Program (BIS). The validation of survey sample shows for the both 
faculties that there are (81.11\%) of students' views are valid and the remaining respondents (18.89 \%) are not valid for statistical analysis. Meanwhile, the validation of survey sample for the faculty of Computers and Information shows that there are $(89.4 \%)$ of students' survey is valid whereas remaining respondents $(10.55 \%)$ are not valid for statistical analysis.

\section{Case study: Current Survey Analysis}

In the absence of empirical studies to assist in the selection of the most significant factors for the cloud computing adoption process in different situation, all relevant factors have been identified and clustered together into three broad clusters of internal, external and technological factors that influence the adoption process of CC in Helwan University. This will be taken up in the following survey analysis, as depicted in figure 3 .

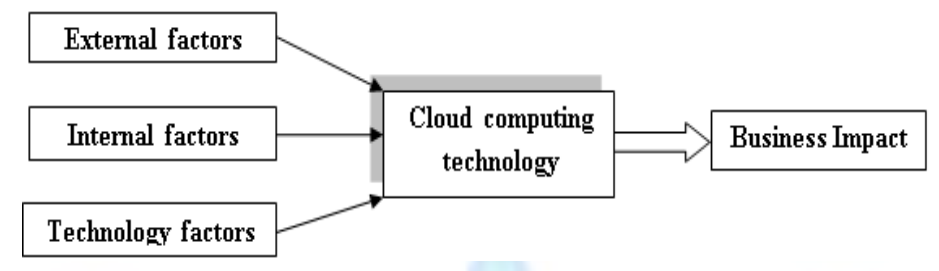

Fig. 3: Factors affecting the $\mathrm{CC}$ adoption process

The survey analysis shows the results of satisfaction level among students for the existing system. Results are expressed in terms of the frequencies in numbers and ratios whereas in the comparison analysis; the Mean (M) and Coefficient of Variation ( $\left.\mathrm{CV}=(\text { Standard deviation/ mean })^{*} 100\right)$ will be used. The survey shows that although the students get some benefits from the existing system services and facilities (21.06\%) but they feel dissatisfied with the standard e-learning services offered by the HELC (41.54\%). In the rest of this subsection the findings of questionnaire survey will be illustrated and analyzed in total for both faculties. The satisfaction level survey is measured by taking into account 14 questions. These questions are grouped into four main clusters based on the relations among the satisfaction level's questions.

As for sample survey students' views, in general, most of the students' sample (44.30\%) based on their responds on satisfaction survey are dissatisfied with the overall services that are offered by HELC in terms of communication, speed of access, the ease of use, skillful, achieving tasks, accuracy, up-to-date, and the needed access time to students' data. Contradictory, students have not positive attitudes of the overall system services which have direct effect on their dissatisfaction feelings of using the existing system. On the other side, the HELC staff agreed that the existing system is unable to provide the whole necessary students' data and information in a sufficient and accurate way. Moreover, they are fairly indifferent towards HELC's students. Based on the survey findings that illustrated above, the following two main conclusions can be drawn: a) Students are dissatisfied with the existing service system and b) HELC staff is indifferent opinions with the existing service level they offer to other faculties.

\section{Awareness Current Survey's Analysis}

The findings show that the most of the students (47.10\%) are not aware by the services that have been offered by HELC. This highest ratio owing to that the center does not provide the students with the required information and knowledge of the way of usage and the functional ideas of the standard e-learning services. In addition to, they believe that the usage of existing system might not improve the educational processes in their academic tasks as well as the interaction between them. The mentioned ratio is as a result of that most of students do not cognizance with the existing system. Consequently, the common attitude between student resulted from the lack of information and knowledge of the system services that offered by HELC.

\section{Technical Current Survey's Analysis}

Generally, most of students' respondents agreed that their dissatisfaction of the services that provided by HELC due to technical obstacles and challenges. These obstacles are such as Internet speed and capacity in download lectures and for up loading their tasks and assignments. This finding thanks to that the students are dissatisfied with the services performance level that offered by HELC (48.99\%) as well as the students did not inform with most of the free services supporting by HELC. Generally, the students approved that they avoid using the existing system. As well as, they do not gain any benefit of using it due to many technical problems that facing them during the use of existing system.

\section{Survey's Analysis for Overall System Services:}

The findings survey approved that the most of students are use the existing system with bad condition in the overall system services $(55.79 \%)$ that offered by HELC. The high ratio references to the technical problems and absences of VLE conceptual base of using e-learning to improve their educational processes. The idea of students who used the system services in good condition (16.71\%) thanks to their individual experiences and skills of dealing with similar types of applications and systems. The questionnaire's findings that considering students and HELC staff, which related to the expected benefits of using the newest system can be summarized as follows: 
In general, HELC staff strongly support the application of newly techniques and they prefer the newly techniques to the existing ones. Moreover, they believed that by the adoption of cloud computing they could gain several benefits such as increasing the information service in terms of quality and time, and improving the staff responsibility and skills.

HELC staff list other benefits as follows: CC can help (1) reduce administrative/ transaction data costs, and (2) provide better information and knowledge about students to the center. In addition, CC; by providing information about students' behavior can help to keep existing students interested and to increase the students' satisfaction.

HSCC and HELC staffs agree that by applying the enhanced framework for e-learning based cloud, there are different benefits and settlements might be achieved, namely it can help to increase (1) the market share and enter new market, (2) the flexibility between HELC' services and students, (3) the ability to innovate, (4) convincing and encouraging the students for the usage of HELC services.

\section{CASE SURVEY ANALYSIS AND FINDING DISCUSSION}

The following figures and explanation show the comparison findings' sample before the implementation of the enhanced technique and after the completed evaluation after the fully implementation of CC in the academic year 2014-2015.

As for satisfaction level, the preceding discussion identified that the satisfaction level survey is measured by taking into account the SERVQUAL instrument via 14 different questions. These questions are grouped into four main clusters based on the relations among the satisfaction level's items for measurements. These clusters are namely: Cluster one (C1) for measuring the usage and ease of use items, Cluster two (C2) for measuring the useful and skillful items, Cluster three (C3) for measuring the saving time in achieving and carrying out the academic tasks items, and Cluster four (C4) for measuring the communication and speed items.

Figure 3 shows the comparisons between the before and after opinion survey regarding the satisfaction level among the students sample in the different adapted features of the enhanced framework for e-learning based cloud. The whole Means of measurements indicate that there are major increasing in the whole clusters measurement's items for both facilities' students sample (by Means; C1: 2.42, C2: 2.42, C3: 2.41, and C4: 2.34) and for the whole satisfaction level (by M: 2.40) in using the enhanced system.

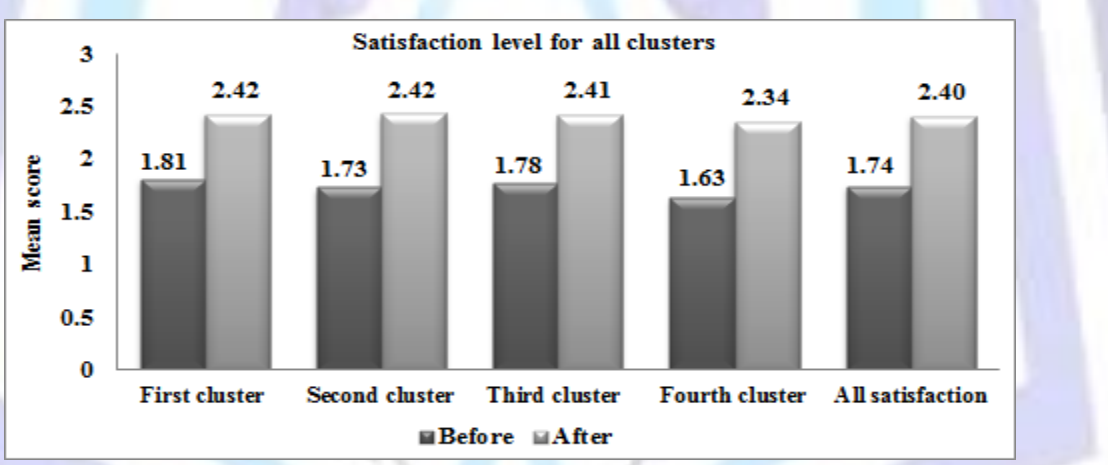

Fig. 3: Students views of satisfaction level for all questioners' clusters

As for the awareness level measure, the comparisons show that there are a major increasing in the awareness level between faculties' students (by total Mean: 2.41), as depicted in figure 4. These high percentages indicate that the enhanced system provides the students with the whole needed information and functions for using the new system which have directly positive reflect on their awareness level. In addition, they are strongly believed that the e-learning based cloud improving their educational processes in terms of achieving the academic tasks and increasing the interaction between them and with their instructors.

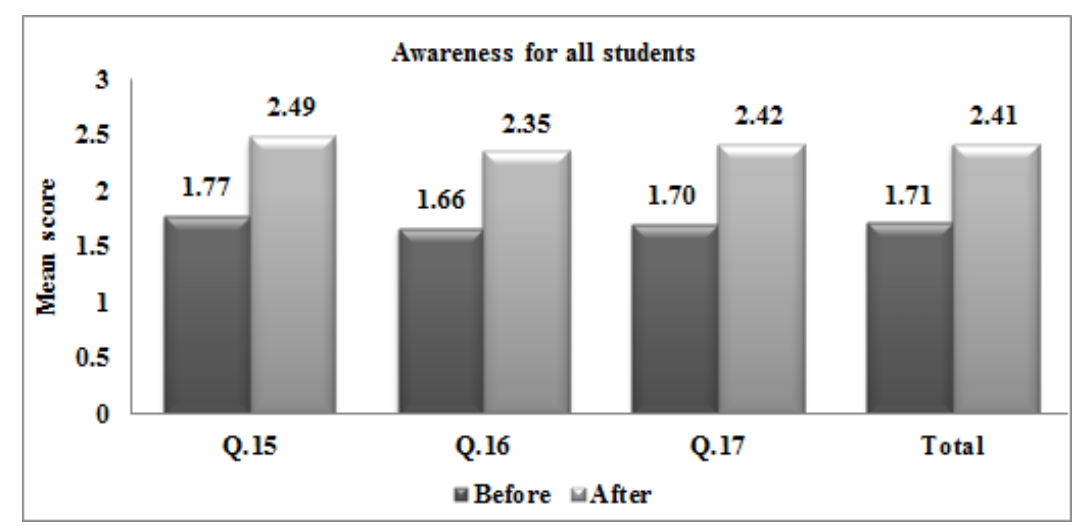

Fig. 4: Students' views of awareness 
As for technical problems, generally most students respondents, agreed that their dissatisfaction in the early survey was due to the technical obstacles and challenges they faced in using old system such as Internet speed and capacity in download lectures and for up loading their tasks and assignments. Whereas, figure 5 shows that the students in both faculties, after the fully implementation of e-learning based cloud, are approved that they gain a various benefits of using the enhanced system in terms of their academic processes without any technical problem could face them during the use of the proposed system (by total Mean: 2.41).

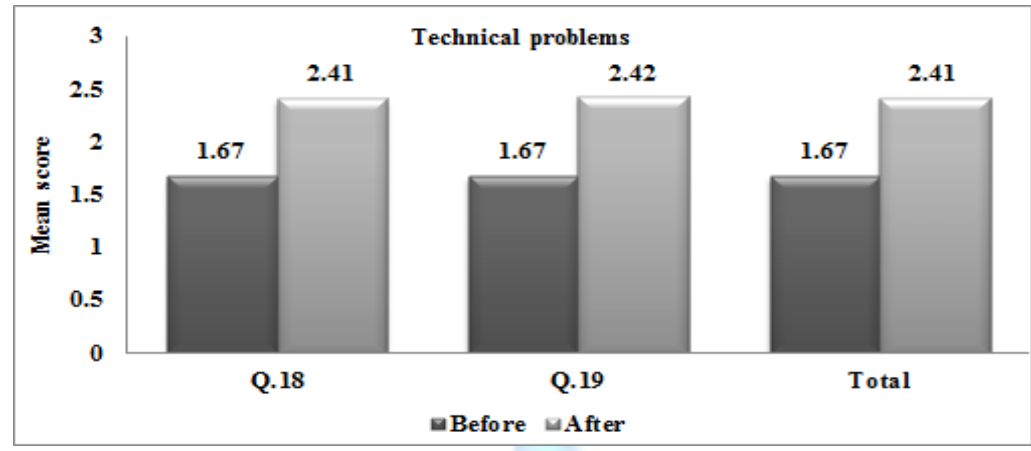

Fig. 5: Students' views of technical problems

As for the findings analysis for overall system services offered by the enhanced technique, the findings approved that the most of students use the services in good condition (by the all Means that depicted in figure 6) with the overall proposed system services. This high ratios reference that the introduction and the fully awareness of the enhanced system in the right way of improving their educational processes, as illustrated in figure 6 . Additionally, students are strongly agreed that the idea of using cloud for e-learning and the conceptual base of VLE for using e-learning improved their educational processes.

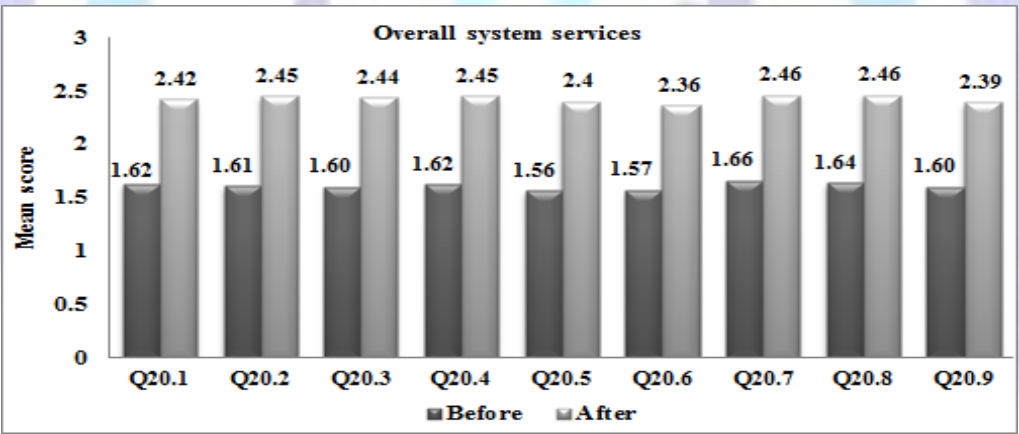

Fig. 6: Students' views overall system services views

To conclude, the findings of implementing the adopted the proposed system equate the study expectations; the findings show that there are a significant increasing in the whole levels of survey in the comparisons of before and after implementation of the proposed system. So, it can conclude that most of the study sample survey is satisfied of the whole proposed system provided by the adapted HSCC system align with HELC, as depicted in figure 7.

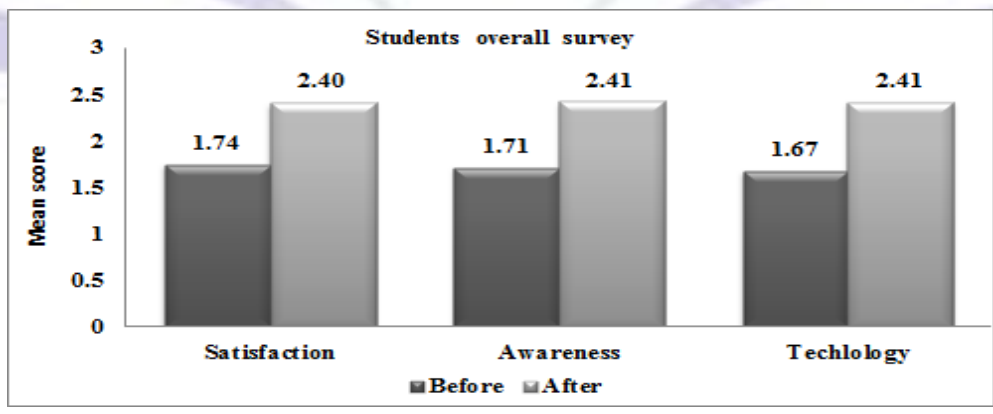

Fig. 7: Students' views of overall survey

\section{CONCLUSION}

The aim of this study is exploratory, building towards understanding and subsequently towards constructive guidance for the adoption process of new technologies in corporate environments. Since the research deals with poorly understood issues in a rich, difficult to control environment, caution ought to be taken in assessing the results. The study is attempting to apply an enhanced cloud framework for e-learning to improve the educational process for Helwan University e-learning system. The findings of this research found that the number of students that use the 
existing system is low; as well the communication between the students and faculty members by mean of technology is likewise low and is not motivated by the actual facilities used by students and faculty in their daily academic life. The expectation of the study respondents compared to the real dealing does not match actual users' needs. The research used an experiment through the adoption of the new enhanced system and used the sampling test thanks to it is a reliable tool to examine and measure the students satisfaction.

To conclude, the overall findings show that the educational process level is significantly increased toward both segments of the targeted sample. Therefore, it can be concluded that the adoption of the enhanced cloud computing framework for e-learning in higher education is expected to improve the educational process via new system functionality besides matching the increasing needs of students, staff, and maximize the benefits that they gain through their online educational experience.

\section{REFERENCE}

[1] Pocatilu, P. 2010. Cloud Computing Benefits for e-Learning Solutions. Oeconomics of Knowledge. 2(1) Pp. 9-14.

[2] POPOVIC, K. and HOCENSKI, Z. 2010. Cloud computing security issues and challenge. 2010. IEEE. Pp. $344-349$.

[3] Qian, L., Luo, Z., Du, Y. and Guo, L. 2009. Cloud Computing: an Overview. Springer-Verlag. Berlin. Heidelberg.

[4] Khedr, A. E., Kholeif, S. A. and Hessen, S. H. Adoption of cloud computing framework in higher education to enhance educational process. International Journal of Innovative Research in Computer Science and Technology (IJIRCST). Volume 3. Issue 3. March - 2015, Pp. 150 -156.

[5] Alexander, B. 2006. Web 2.0 a new wave of innovation for teaching and learning. Available from: http://www.educause.edu/ir/library/pdf/ERM0621

[6] Bora, U. and Ahmed, M. January 2013. E-Learning using Cloud Computing. International Journal of Science and Modern Engineering (IJISME). Vol. 1. Issue. 2. Pp. 9-13.

[7] Al-Zoube, M. June 2009. E-Learning on the Cloud. The International Arab Journal of e-Technology. Vol. 1. No. 2. Princess Sumaya University for Technology. Jordan. Pp.58-64.

[8] Nasr, M. and Ouf, S. 2006. A Proposed Smart E-Learning System Using Cloud Computing Services: PAAS, IAAS and Web 3.0. (IJET) . Vol. 7. Issue 3. Helwan University. Cairo. Egypt. Pp. 19-24. Available from: http://dx.doi.org/10.3991/ijet.v7i3.2066

[9] Konrad, M. 2002. Attention to Process and People are Key to Technology Adoption. Software Engineering Institute. Pittsburgh. PA. USA.

[10] Premus, R. 2002. Moving Technology from Labs to Market: A Policy Perspective. Technology Transfer and Commercialization. Int. Vol. 1. Nos. 1/2. Pp. 22-39.

[11] Furrer, O., Liu, B. and Sudharshan, D. 2000. The Relationships between Service Culture and Service Quality Perceptions-Basis for Cross-Cultural Marker Segmentation and Resource Allocation. Journal of Service Research. Vol. 2. No. 4. Pp. 355-371

[12] Khedr, A. E. 2008. Adoption of new technologies in a highly uncertain environment: The case of Knowledge Discovery in Databases for Customer Relationship Management in Egyptian public banks. PhD. Dissertation LIACS. Leiden University. Leiden. The Netherlands.

[13] Kamakura, W., Mittal, V., De Rosa, F., and Mazzon, J. 2002. Assessing the Service-Profit Chain. Marketing Science. Vol. 21. No. 3. Pp. 294-317.

[14] Geroski, P. 2000. Models of Technology Diffusion. Research Policy. Vol. 29. No. 4. Pp. 603-625.

[15] Davis, S. and Wiedenbeck, S. 2001. The mediating effects of intrinsic motivation, ease of use and usefulness perceptions on performance in first-time and subsequent computer users. Interacting With Computers. Vol. 13. Pp. $549-580$

[16] Campbell, K. and Helleloid, D. 2002. Perspective: An Exercise To Explore The Future Impact Of New Technologies. The Journal of Product Innovation Management. Vol. 19. Pp. 69-80.

[17] Kwan, R., Fox, R., Chan, F. and Tsang, P. Enhancing Learning Through Technology: Research on Emerging Technologies and Pedagogies. World Scientific. 2008.

[18] Khedr, A. Towards Three Dimensional Analyses for Applying E-Learning Evaluation Model: The Case of ELearning in Helwan University. International Journal of Computer Science Issues (IJCSI). Vol.9. Issue: 4. No.1. July 2012. Pp.161-166.

[19] Kondo, D., Javadi, B., Malecot, P., Cappello, F. and Anderson, D. 2009. Cost-Benefit Analysis of Cloud Computing Versus Desktop Grids. Parallel and Distributed Processing (IPDPS), IEEE International Symposium on 2329 May 2009. Rome. Pp. 1-12.

[20] Nandi, S., Garrawal, B. and Mantri, A. October 2010. Dynamic Higher Education and Research Cloud. at ASE $9^{\text {th }}$ Global Colloquium on Engineering Education. Singapore. 
[21] Berl, A., Gelenbe, E., Girolamo, M., Giuliani, G., Meer, H., Dang, M. Q. and Pentikousis, K. 2009. Energy-Efficient Cloud Computing. Bowling Green State University. www.comjnl.oxfordjournals.org

[22] Richards, G., McGreal, R. and Stewart, B. December 2010. Cloud Computing, and Adult Literacy: How Cloud Computing Can Sustain the Promise of Adult Learning. A report on emerging technology for the alpha plus project. Cloud Computing and Adult Literacy. Available from: http://auspace.athabascau.ca.

[23] Basak, D., Toshniwal, R., Maskalik, S. and Sequeira, A. December 2010. Virtualizing networking and security in the Cloud. Newsletter ACM SIGOPS Operating Systems Review. Vol. 44. No. 4. ACM New York. NY. USA.

[24] Madan, D, Pant, A., Kumar,S., Arora, A. February 2012. E-learning based on cloud computing. International Journal of Advanced Research in Computer Science and Software Engineering (IJARCSSE). Vol. 2. Issue 2.

[25] Takabi, H., Joshi, J. B. D. and Ahn, G. J. November/December 2010. Security and Privacy Challenges in Cloud Computing Environments. IEEE computer and reliability societies.

[26] Xiao, Z., Xiao, Y. and Senior Member. second quarter 2013. Security and Privacy in Cloud Computing. IEEE communications surveys \& tutorials, Vol. 15. No. 2.

[27] Mell,P. What's Special about Cloud Security?. July/August 2012. IT Pro. published by IEEE computer society.

[28] Duan, J. C., Zhang, T. and Fan, J. 2011. Study on the security models and strategies of cloud computing. Published by Elsevier Ltd.

[29] Jing, X. and Jian-jun2, Z. 2010. A Brief Survey on the Security Model of Cloud Computing. IEEE .

[30] Engr: Shaikh, F. B. and Haider, S.2011 Security Threats in Cloud Computing. IEEE

[31] Sato,H. 2010 . A Cloud Trust Model in a Security Aware Cloud. SAINT. pp.121-124.

[32] Vouch, M. A. 2008. Cloud Computing Issues, Research and Implementations. Journal of Computing and Information Technology. Pp 235-246.

[33] Kaur, G. and Chawla, S. June 2014. Cloud E Learning Application: Architecture and Framework. SSRG International Journal of Computer Science and Engineering (SSRG-IJCSE). Vol. 1. issue 4. India.

[34] Kumar, G., and Chelikani, A. 2011. ANALYSIS OF SECURITY ISSUES IN CLOUD BASED E-LEARNING. Master thesis in Informatics

[35] Alshwaier, A., Youssef, A., and Emam, A. January 2012. A NEW TREND FOR E-LEARNING IN KSA USING EDUCATIONAL CLOUDS. Advanced Computing: An International Journal (ACIJ). Vol.3. No.1. Pp. 81-97.

[36] LAISHENG, X. and ZHENGXIA, W. 2011. Cloud Computing: A New Business Paradigm for E-learning. IEEE. Pp716-719.

[37] Mircea, M., and Andreescu, A. 2011. Using Cloud Computing in Higher Education: A Strategy to Improve Agility in the Current Financial Crisis. IBIMA. Pp. 1-15. Available from: http://www.ibimapublishing.com

\section{Author's Biography}

Dr. Ayman Elsayed Khedr is an associate professor of information systems, Department of Information Systems, Faculty of Computers and Information, Helwan University, Cairo, Egypt. His research interests include several filed such as Business intelligent, data mining, decision support system, cloud computing, and adoption of new technologies. ayman_khedr@helwan.edu.eg

Dr. Sherif Abd Elkader Kholeif is an assistant professor of information systems, Faculty of Computers and Information, Helwan University. His research interests include several fields such as Web application security, intelligent agents, and data mining. sherifkholeif@yahoo.com

Shrouk Hossam Eldin Hessen is an IT developer in Ismailia Court and a master researcher in the department of Information Systems, Faculty of Computers and Information, Helwan University, Cairo, Egypt. Her research interests are in Cloud computing, e-learning, adoption of new technologies, and big data. shroukhessen@gmail.com 